\title{
Delivering Development to Gender-conscious Communities in S. Korea: What Factors Matter?
}

\author{
Taewook Huh* and Yunyoung Kim**
}

\begin{abstract}
This paper aims to suggest an alternative monitoring framework for the WFC (Women-Friendly City) project that can have an impact on the performance of the WFC project. In particular, this study looks at the mutual relationships between the factors of the framework that was suggested through the analysis of the project-related interviewees' accounts of qualitative research. Path analysis was carried out to analyze the relationship between the six variables independent (Institutional Resources), parametric (PPCo or Public-Public Cooperation), Education, PPP (Public-Private Partnership) and dependent (Performance and (Gender) Representation). As a result, it was found that Institutional Resources, PPCo, and PPP had a significant influence on Performance and Representation. In particular, there were four statistical associations (paths): Institutional Resources $\rightarrow$ Performance, PPCo $\rightarrow$ Performance, PPCo $\rightarrow$ Representation, and $\mathrm{PPP} \rightarrow$ Representation $(\mathrm{p}<0.05)$.
\end{abstract}

Keywords: Women-Friendly City, Institutional Resources, Public-Public Cooperation, Public-Private Partnership, Gender Representation, Path Analysis

\section{INTRODUCTION}

Since the 1990s attention has been paid to the concept of 'women-friendliness' in urban places. In fact, in 1994, the OECD started to discuss the issues of women and the urban environment, and in 1996, the Second United Nations Conference on Human Settlements was held in Istanbul, seeking to achieve improvements in the living environment of all people, with special attention to the needs and contributions of women whose quality of life and participation in development have been hampered by exclusion and inequality. 'Women-friendliness' in urban places is a newly-emerging

\footnotetext{
* First \& Corresponding Author, Research Assistant Professor, Moon Soul Graduate School of Future Strategy, KAIST, e-mail: twhuh@kaist.ac.kr, huh9595@naver.com.

** Co-author, Associate Research Fellow, Department of Urban Management, Incheon Development Institute.
}

Manuscript received June 19, 2016; out for review June 23, 2017; review completed August 4, 2017; accepted August 7, 2017.

The Korean Journal of Policy Studies, Vol. 32, No. 2 (2017), pp. 63-83.

(C) 2017 by the GSPA, Seoul National University 
value that is needed for women's robust economic and social activities, and also for sustainable childbirth and child-caring.

In S. Korea, governmental and non-governmental actors are trying to form a fundamental basis for gender-conscious city space policies. In particular, since 2009, the Women-friendly City project (WFC) was initiated and carried out at the national level to seek an alternative perspective on the gender approach to cities. It can be defined as "local communities where men and women equally participate in the regional policy and development process, and where the growth and safety of women are assured" (Moon and Ma, 2010: 3-4). In S. Korea it is generally regarded that the complete separation between residential and business areas defined women as the household manager and constrained women's social activities.

This study notes that the WFC project can be understood in the context of redefining gender roles in public space. Dividing private and public spaces has been generally accepted in Korean society, which has worked to fix women's roles only in the home and private spaces. It can be regarded as 'the dichotomy of gender roles' (Chapman, 2004; McDowell, 1999; Vafaei et al., 2016), separating the gender roles with men in public spheres and women in private spheres. However, although such spatial separation discourse is inappropriate because of a significant expansion of women's roles (activities) in public areas, the spatial environment in daily life has not sufficiently reflected these changed circumstances.

This paper aims to suggest an alternative for the monitoring framework of the WFC project by particularly reflecting the criteria of the impact evaluation. Also, we try to analyze what factors of the framework matter, and to what extent they have an impact on the performance and results of the WFC project. For this, the focus group interview (FGI) and individual interviews with the project-related local government staff, experts (researchers of women's policy institutes), and civic group (women campaign) members who have carried out the consulting works - as the WFC committee members - for the WFC project were conducted six times from January to July 2014. A total of 14 interviewees participated in the semi-structured interviews and FGI that consist of 10 questions highlighting how the existing monitoring criteria work in the field, what problems the respondents faced, and how to advance the alternatives. For the anonymity of the respondents, this paper utilized a numbering system in relation to respondents' quotation. Also, in particular, the path analysis was carried out in order to analyze the mutual relationship between the factors (variables) and reveal the path constitution in a thorough way. The statistical package STATA 13.0 was used. This study is based on the 2014 monitoring data of 50 local governments in women-friendly designated cities in S. Korea from 2010 to 2014. 


\section{WOMEN-FRIENDLY CITY (WFC) PROJECT AND THE EVALUATION PRINCIPLES}

\section{The Rationale and Status of the WFC Project}

The Korean government (Ministry of Gender Equality \& Family) created the WFC project, which seeks equal participation between men and women in decision-making and transformation of policy direction and implementation, based on the approach of 'gender mainstreaming.' Gender mainstreaming is the public policy concept of assessing the different implications for women and for men of any planned policy action, including legislation and programs, in all areas and at all levels (Kim and Moon, 2008a), (Song and Park, 2013). ${ }^{1}$

The WFC project relates to the gender-conscious city space policy, focusing on women's participation in the urban policy, and the gender-conscious perspective integrated into all areas of local communities - politics, economy, and social and cultural life. The project promotes the vision, "community policy-taking care of quality of life and happy local community engaging women", incorporating four values - equality, care, environmental-friendliness, and communication, and five desired targets (see the below Figure 1.) (Moon and Ma, 2010: 3-10).

Figure 1. The Vision, Values and Targets of the WFC Project

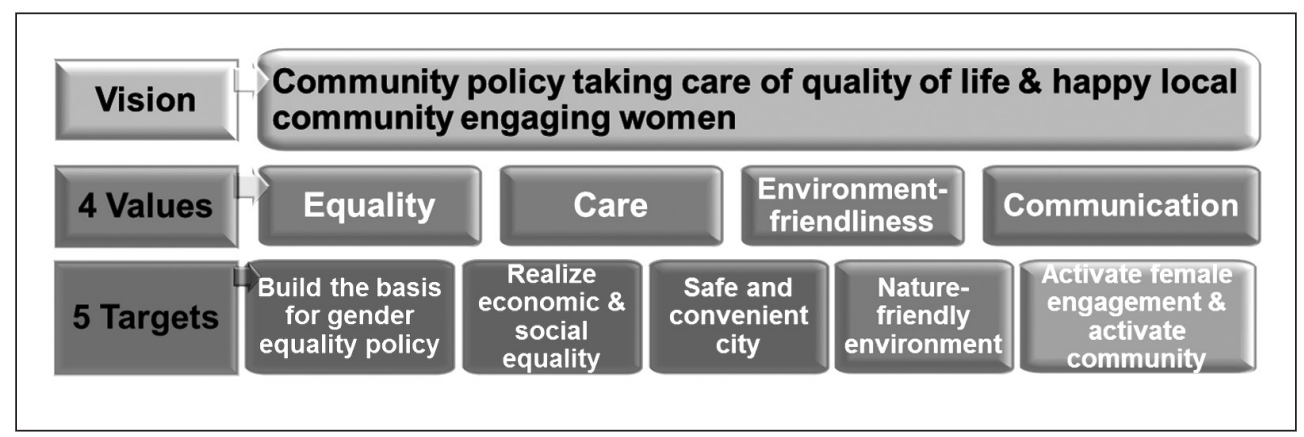

The Ministry of Gender Equality \& Family designates some of the applied communities as a 'Women-friendly City' through the screening process based on the criteria.

1. The paradigm was first introduced at the Fourth World Conference on Women, Beijing in1995. 
Figure 2. 50 Women-friendly Cities designated up to 2013

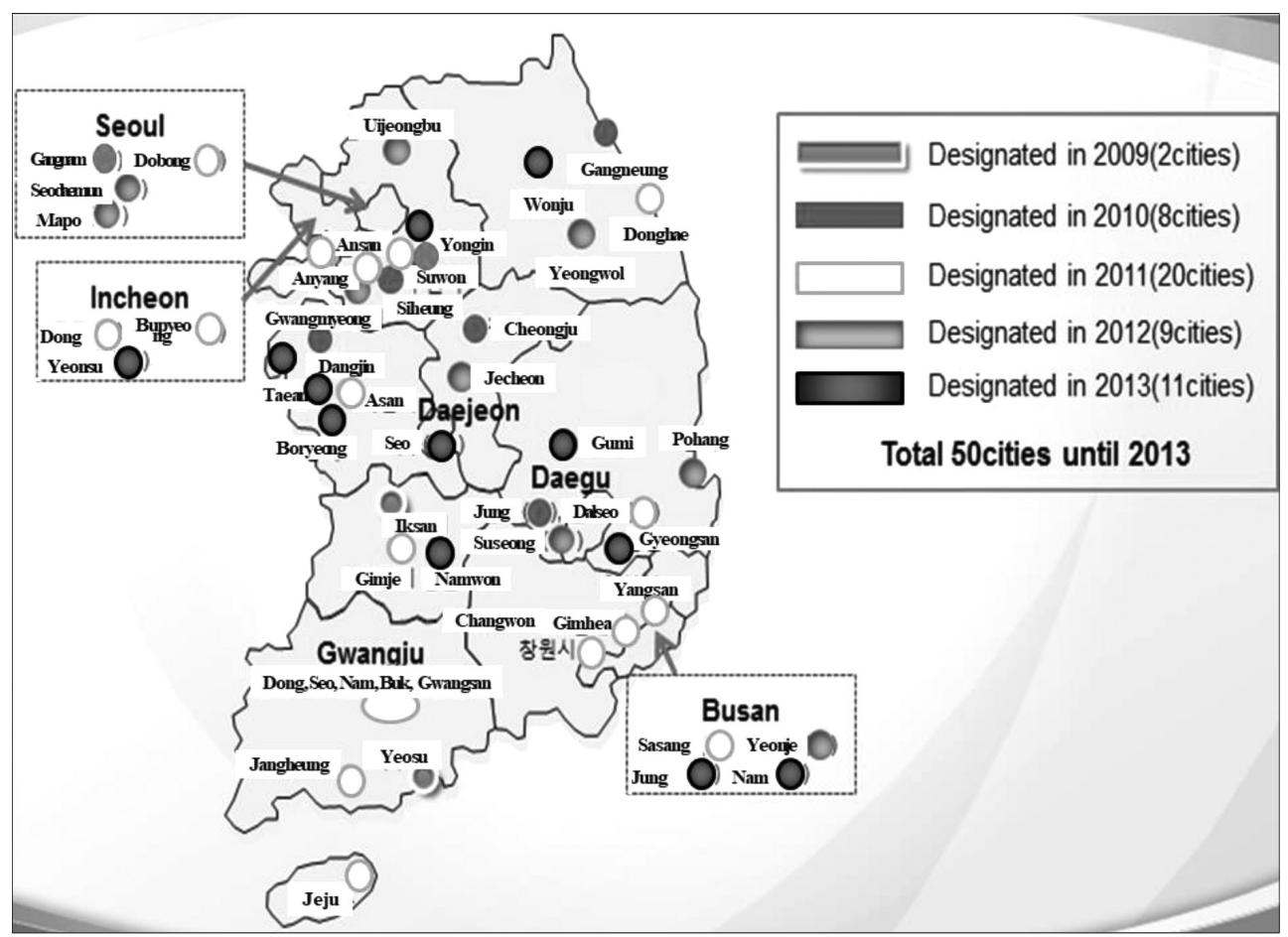

Sources: Choi, et al. 2014. The Creation Plan of Women Jobs through the Revitalization of Women Participation of Citizen Autonomy(revised).

After designating the cities, the aforesaid ministry and the Korean Women's Development Institute (KWDI) carried out annual implementation monitoring. Since 2009, (as illustrated in Figure 2.), a total of 50 cities have been designated (i.e. $22 \%$ of the total local government communities (227) in S. Korea).

\section{The Necessity of Advancing the Evaluation Principles}

Meanwhile, although several outcomes of evaluation appear to be good examples for further development of the WFC project (Choi, et al. 2013), the WFC project lacked empirical evidence that demonstrated specific factors of the WFC project that worked, how they were related to each other, and the extent to which they have any influence on the performance of the project. This study, as Figure 3. explains, notes that the key characteristics of the WFC project are required to reflect the features derived from the theoretical discourses of 'gender regime,' 'bureaucratic system' 
'space and civil rights,' and 'gender in city space.' The WFC project aims to tackle gender inequality issues, as argued above, and therefore it must pay attention to the power relations (patriarchal system and gender regime), the dominant-subordinate relationship between men and women, and also the production relation characterized by the gender division of labor and unfair salary gap (Halford, 1992; McDowell, 1999). The patriarchal relationship may be realized through a bureaucratic system which government generally maintains as a barrier to change (Halford et al., 1997; McDowell, 1999; Kim and Moon, 2008b). In particular, as the interviewees 4 and 5 argued, in the local public administration, gender issues are openly ignored and gender policies may be hindered by 'bureaucratic selfishness,' and an apathetic attitude of organizations.

Figure 3. Contextual Link between the Theoretical Discourses and the WFC Project's Principles

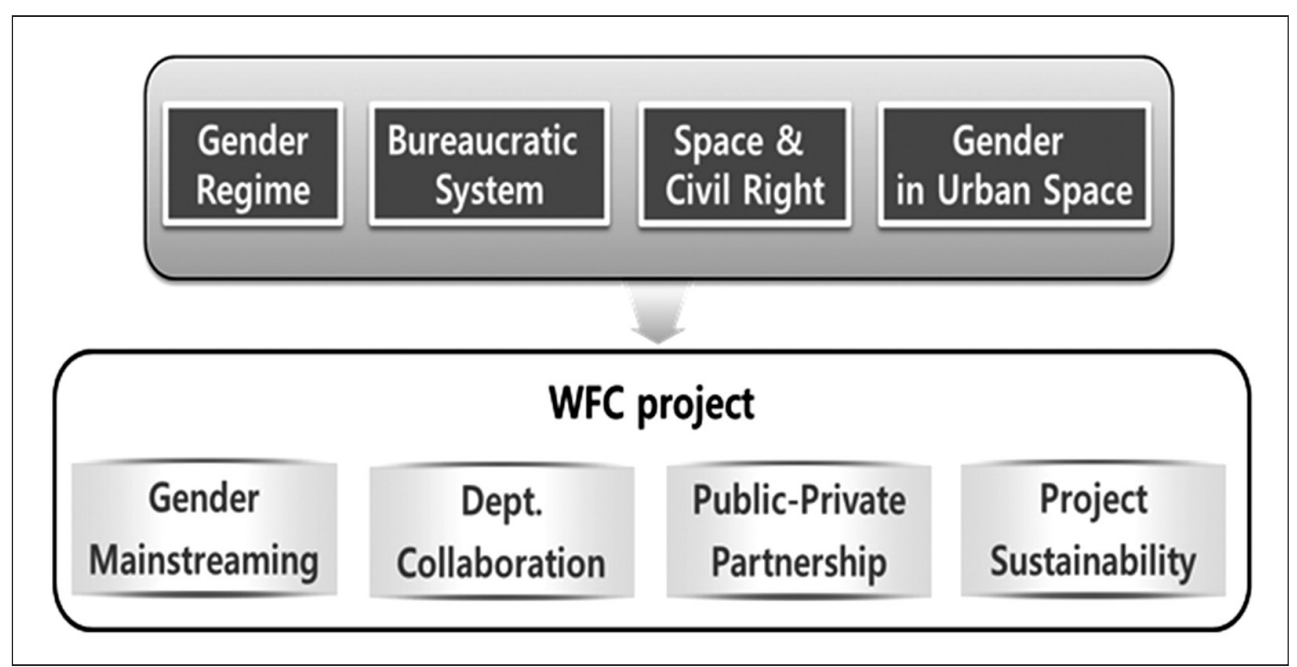

The theoretical discourses of 'space and civil rights' and 'gender in city space' are mutually connected in that space is characterized by a variety of social relations, including gender, class, race, age, and so on (Laws, 1994; McDowell, 1999; Valentine, 1990). City space works as a driver to reconfigure social relations, which can actually divide a special social status from a geographical place that individuals and groups occupy (McDowell, 1999; Pain, 1991; Valentine, 1990). City space in daily life is able to operate as a catalyst to constrain women's physical, social and economic activities and reinforce a dominant-subordinate relation between genders (Hayden, 1995; Laws, 1997). 
As many interviewees $(1,3,7,8,12$, and 13) suggested, we note that the evaluation framework of the WFC project is required to embrace the above theoretical discourses. It can be realized by including the main principles of the WFC project such as 'gender mainstreaming' in the urban space at different levels (individual, communal, institutional, and etc.); 'department collaboration,' namely collaborative works among departments in each local government; 'public-private partnership' embracing various stakeholders from different sectors by establishing civic participation committees; and 'project sustainability' through the performance and outcomes of the project.

\section{Evaluating the WFC project - Setting up Alternative Principles}

The evaluation framework of the WFC project has been conducted by the Korean Women's Development Institute since 2012. The implementation monitoring has been conducted in order to diagnose the current situation - performance, outcome, barriers, and etc. - of the WFC project by analyzing the current status through the implementation monitoring indicators, and then to provide a feedback on it in order to improve the conditions (Moon and Ma, 2012; Choi, et al. 2013) The existing monitoring framework consisted of three major criteria (indicators) (Moon and Ma, 2012; Choi, et al. 2013): (1)'responsibilities,' (2)'implementation process,' and (3)'the contents and the extent of detailed projects.' However, as interviewees 3, 7, 11, 13 pointed out, the existing monitoring framework lacks the ability to identify appropriate outcomes and outcome measures; it is not able to define the measurable outcomes (impact) of the WFC project; there exists a lack of setting up specific performance objectives and measurable indicators.

In line with seeking an alternative, particularly based on the interview results, the existing monitoring framework needs to deal with several major issues: identifying appropriate outcomes (impact) and outcome measures, defining the measurable outcomes (impact) of the WFC project, and setting up specific performance objectives and measurable indicators.

Since 2012, although I(We) have been involved in the WFC monitoring process, I(we) was not very aware of what the measurement means... actually less easy to figure out which ones are for outcomes and results.... In relation to this, I(we) think such outcomes differ according to the WFC projects' period - the cities designated from 2010 to 2014. (interviewees 1, 2, 6, 8, and 11)

In this regard, the alternative monitoring framework can be created by embracing the principles of Theory of Change including 'a pathway of change or change frame- 
work' (Connell and Kubisch, 1998; Kubisch, 1996). The thrust of it is that through focusing on the features of 'Theory of Change' evaluation, the monitoring framework can capture systematic and cumulative links between activities and outcomes of the WFC project initiative (Connell and Kubisch, 1998), and also can give an explanation of how and why the WFC project initiative works (Weiss, 1995). As explained in Table 2 . below, this study suggests the Women-Friendly Cities can be divided into two levels according to their designated years - from first to fifth year: Level I ('Spawning,' 1-2 year cities (20)), Level II ('Settling,' 3-5 year cities (30)). ${ }^{2}$

The alternative framework consists of three main areas: (1) 'Implementation Based on Gender Equality Policies,' (2) PPP, and (3) 'Implementation Performance \& Typical Projects,' which theoretically embrace the directions and objectives of the WFC project. In particular, the indicators and the detailed indicators are reviewed and selected from the existing monitoring framework for 2011 and 2012. Also, through the alternative framework we can take a more realistic approach in relation to capturing the data when identifying the output and outcomes, which was agreed to by the interviewees.

$\mathrm{I}(\mathrm{We})$ have encountered/heard various problems happened in monitoring the WFC projects, detailed ones in each local government. For example, less easy to pick up specific performance and results for the detailed projects, and to reflect the public-private partnership (cooperation) efforts....but this monitoring framework may be much better to work for capturing and analyzing the fieldwork performances and outcomes... particularly the details of how the projects were constructed and resulted in....(Interviewees 2, 7, 9, 10, and 13)

As Table 1. below explains, in Level I ('Spawning'), the first area includes (1) 'Administrative Organization on Gender Equality,' (2)'Planning of Project Implementation,' (3)'Supporting the Capacity of Civil Servants \& Citizens,' and (4)'Arranging the System for Cooperation between Departments;' the second area consists of (5)-(A) 'Mechanism of Participation/Cooperation;' and the third area ('Implementation Performance \& Typical Projects') involves (6) 'Gender-Sensitive Monitoring on Institutions/ Project,' (7)'Exploring Detailed Projects,' and (8)'Utilizing Typical Projects.'

Through Level II ('Settling'), this study develops some of the indicators in an evolving way. In the first area, the indicator of (2)'Institutional Support for Project Revitalization' is picked up in the context of the 'Settling' level, rather than remaining in 'Planning of Project Implementation' in the 'Spawning' level, and the detailed indicator 'enacting/revising WFC related ordinances' is also added. In line with this, the

2. It may be able to evolve to more levels (three, four, five), according to the development of the WFC project in the future, for example, to a 'mature' level. 
Table 1. The Alternative Monitoring Framework of the WFC Project

\begin{tabular}{|c|c|}
\hline Main Areas & Indicators \\
\hline \multirow{4}{*}{$\begin{array}{l}\text { Implementation } \\
\text { Based on } \\
\text { Gender } \\
\text { Equality } \\
\text { Policies }\end{array}$} & $\begin{array}{l}\text { (1) Administrative } \\
\text { Organization on } \\
\text { Gender Equality }\end{array}$ \\
\hline & $\begin{array}{l}\text { (2) Planning of Project } \\
\text { Implementation }\end{array}$ \\
\hline & $\begin{array}{l}\text { (3) Supporting the } \\
\text { Capacity of Civil } \\
\text { Servants \& Citizens }\end{array}$ \\
\hline & $\begin{array}{l}\text { (4) Arranging the } \\
\text { System for } \\
\text { Cooperation btw } \\
\text { depts }\end{array}$ \\
\hline $\begin{array}{l}\text { Public-Private } \\
\text { Partnership }\end{array}$ & $\begin{array}{l}\text { (5)-(A) Mechanism of } \\
\text { Participation/ } \\
\text { Cooperation }\end{array}$ \\
\hline \multirow{3}{*}{$\begin{array}{l}\text { Implementation } \\
\text { Performance } \\
\& \\
\text { Typical Projects }\end{array}$} & $\begin{array}{l}\text { (6) Gender-Sensitive } \\
\text { Monitoring on } \\
\text { Institutions/Projects }\end{array}$ \\
\hline & $\begin{array}{l}\text { (7) Exploring detailed } \\
\text { projects }\end{array}$ \\
\hline & $\begin{array}{l}\text { (8) Utilizing the typical } \\
\text { projects }\end{array}$ \\
\hline
\end{tabular}

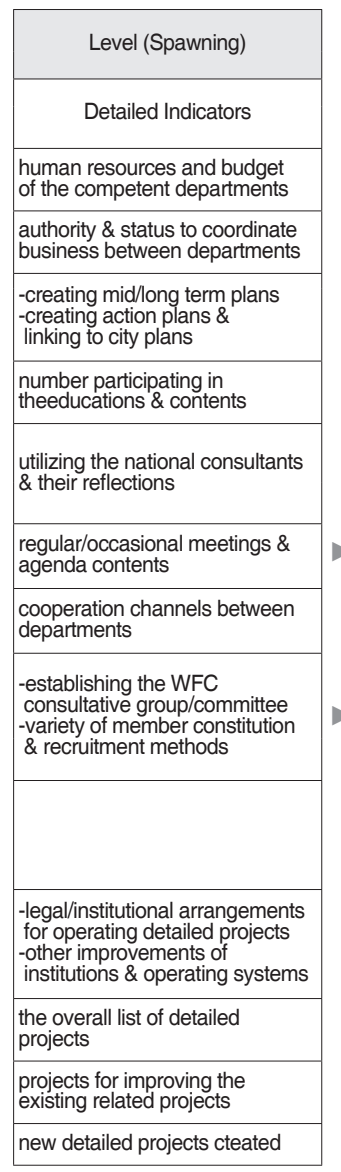

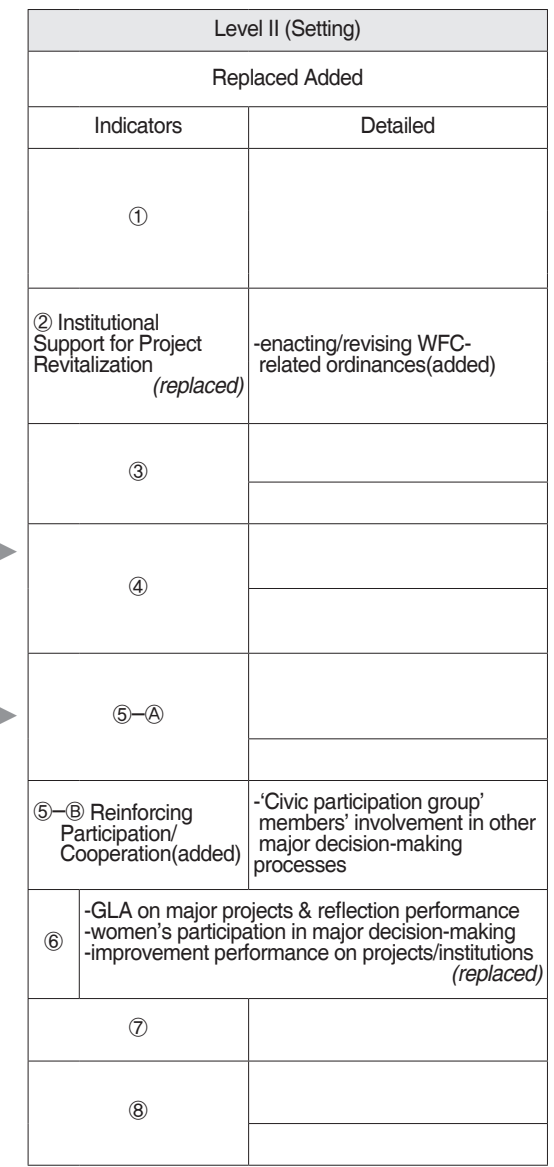

indicator of (5)- B) 'Reinforcing Participation/Cooperation' in the area of PPP and the detailed indicator of 'Civic participation group members' involvement in other major decision-making processes' are added. Also, in the area of 'Implementation Performance \& Typical Projects,' the detailed indicator of 'GIA (Gender Impact Assessment) on major projects \& reflection performance,' 'women's participation in major decision-making,' and 'improvement performance on projects/institutions' replace the existing ones in Level I.

In terms of the alternative monitoring framework, many interviewees (Interviewees $1,3,4,11$, and 14) expressed their satisfaction with the process of drafting the monitoring framework, compared to the existing one; they said that "although this might not be enough to carry out the monitoring works in the fields robustly .... it should be 
a more realistic approach to reveal the factors, which have more influence on the project performance and results, and their mutual relationship in the end". To reiterate, unlike the existing monitoring framework, the alternative one takes into account the repercussions of the WFC project in the field by comprehending the gravity of the multistage outcome indicators in the Level I ('Spawning') and II ('Settling'). In addition, the alternative monitoring framework retains the meaning of integrating the theoretical discourses (including 'bureaucratic system,' 'space and civil right,' and 'gender in city space') into the WFC projects' principles (including 'department collaboration' 'public-private partnership,' and 'project sustainability') which are reflected in the above areas and indicators.

\section{DATA SOURCES AND STATISTICAL MEASURES}

This study adopts the path analysis, which is a part of regression analyses, including path coefficients, in order to look at the extent to which the alternative monitoring framework corresponds to WFC project field results, particularly, which indicators of the framework are mutually related to each other, based on the field data. The path coefficients refer to 'standardized regression coefficient: Beta,' which is expected as a variable. This can be understood as a net change of dependent variables influenced by the change of standard deviation among pre-determined variables. To calculate the path coefficient, the equation of path analysis is required, which is generally expressed as 'effect variable $\sum$ (path coefficient $\mathrm{x}$ caused variable + paths $\mathrm{x}$ confounding)' (Bohrnstedt and Knoke, 2002: 377-379).

In particular, the Partial Least Square method (hereinafter, 'PLS method') is chosen for the study. Methods used to estimate a structural equation model (path analysis is one such method) contain Maximum Likelihood (hereinafter, 'ML method'), Least Square (hereinafter, 'LS method'), and 'PLS method' (Nora, 2004). PLS verifies the significance through a statistical t-test after correcting standard errors, by using bootstrapping (Wolfle, 2003). In addition, this study notes that the minimum required sample size has been proposed in the PLS method (Marcoulides and Saunders, 2006), which can be measured through statistical power analysis with a value of 36 . The minimum sample size is satisfactory because its sample cases are 50 in this study. The statistical package used for PLS analysis in this study is STATA 13.0.

In this study, as shown in Figure 4, six statistical variables are presented, reflecting on the WFC project's principles suggested in chapter II: 'gender mainstreaming,' 'department collaboration,' 'public-private partnership,' and 'project sustainability.' First, the 'Institutional Resource' variable is a representative one of the WFC project's 
institutional setting and groundwork, which is composed of 'administrative personnel number,' 'revision of ordinance number,' and 'execution budget.' 'Institutional Resources' is to highlight the 1st area of the alternative monitoring framework 'Implementation Basis on Gender Equality Policies' —, including the four indicators: (1), (2), (3), (4).

Figure 4. The Composition of Variables based on the WFC Principles \& the Monitoring Framework

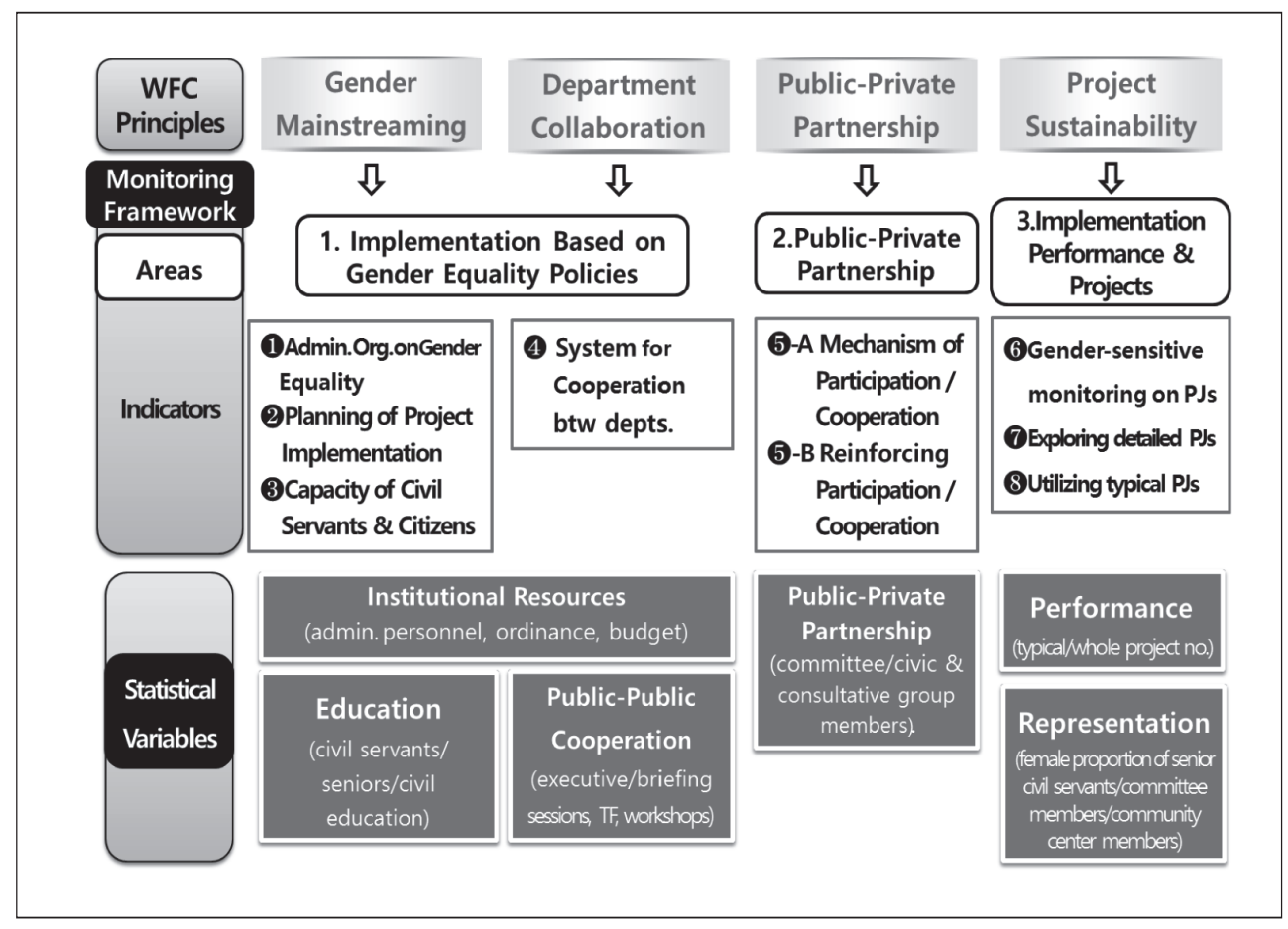

The variable 'Education' exhibits the current state of education to strengthen the capability of civil servant and citizen. The variable consists of 'civil servants' education' (proportion to the whole number), 'seniors' education' - higher than the position of deputy directors (proportion), and civil education (time). 'Education' is also in line with the first area of the alternative monitoring framework, with a solid link to the indicator (3). The variable of 'Public-Public Cooperation' (PPCo) examines whether a bureaucratic system has been arranged for collaboration among departments in the local governments and how it works, which is looked at through 'executive sessions,' 'briefing sessions,' 'WFC task force,' and 'workshops' for seeking tasks (number). 
'PPCo' is related to the first area of the alternative monitoring framework, and particularly to the indicator (4).

The variable of 'Public-Private Partnership' (PPP) considers the current situation of civic participation and examines the cooperation between the public sector and the private (voluntary) sector (Huh, 2017). For this, whether the WFC Development Committee was established, the diversity of committee members, and the recruitment method were examined in detail. 'PPP' directly represent the second area of the alternative monitoring framework, 'Public-Private Partnership,' and clearly includes the two indicators: (5)-A, (5)-B.

'Performance' variable examines the current status of the WFC project performance in detail, which particularly involves a 'typical project number' (presented by each WFC's local government) and a 'whole project number' (total in a process). The 'Representation' variable estimates the female proportion of senior civil servants, the women proportion of WFC committee members, and of the local community center members. The variables of 'Performance' and 'Representation' are in line to represent the third area of the alternative monitoring framework (Implementation Performance \& Typical Projects), and the three indicators: (6), (7), (8).

This research adopts the path analysis, consisting of one independent variable (Institutional Resources), three parametric variables (PPCo, Education, and PPP), and two dependent variables (Performance, Representation), based on the alternative monitoring framework. This highlights and summarizes ten mixed qualitative and quantitative indicators: 5 indicators of the Implementation Basis on Gender Equality Policies; 2 indicators of the PPP; and 3 indicators of the Implementation Performance \& Typical Projects. In fact, the independent variable, one of three parametric indicators, Public-Public Cooperation ('PPCo') is to highlight the first area as well as applying the quantitative detailed indicators of executive sessions, briefing sessions, WFC task force, and workshops for seeking tasks (number). Also, 'Education' is to highlight the first area by using the detailed indicators of civil servants' education (proportion to the whole number), seniors' (of a higher rank than deputy directors) education (proportion), and civil education (time). 'PPP' is to summarize the second area, by applying the detailed indicators of WFC committee members, consultative group members, and civic group members.

One of two dependent indicators, 'Performance' is to highlight the third area, the Implementation Performance \& Typical Projects, by using the detailed indicators of typical project number and whole project number. Also, 'Representation' is to highlight the third area by applying the detailed indicators of the female proportion of senior civil servants (deputy directors), the female proportion of committee members, and the female proportion of community center members. In particular, as Figure 5. 
illustrates, the above six variables are characterized by one independent variable (Institutional Resources), three parametric variables (PPCo, Education, and PPP) and two dependent variables (Performance and Representation).

All independent, parametric and dependent variables utilized for this lie in close relationships. In addition, the path coefficients related to 'Institutional Resources' variable reveal a direct effect. An indirect effect refers to a path effect through an intermediate variable and more. PPCo, Education, and PPP are related to an indirect effect. The total effect is defined as the sum of the total direct effect and total indirect effect generated between variables. The relationship between independent variables (= measured indicators) and dependent variables and path structure, including exogenous and endogenous variables, can be expressed in the following diagrams and graphs.

Figure 5. Path Diagram for Hypothesized Model Predicting

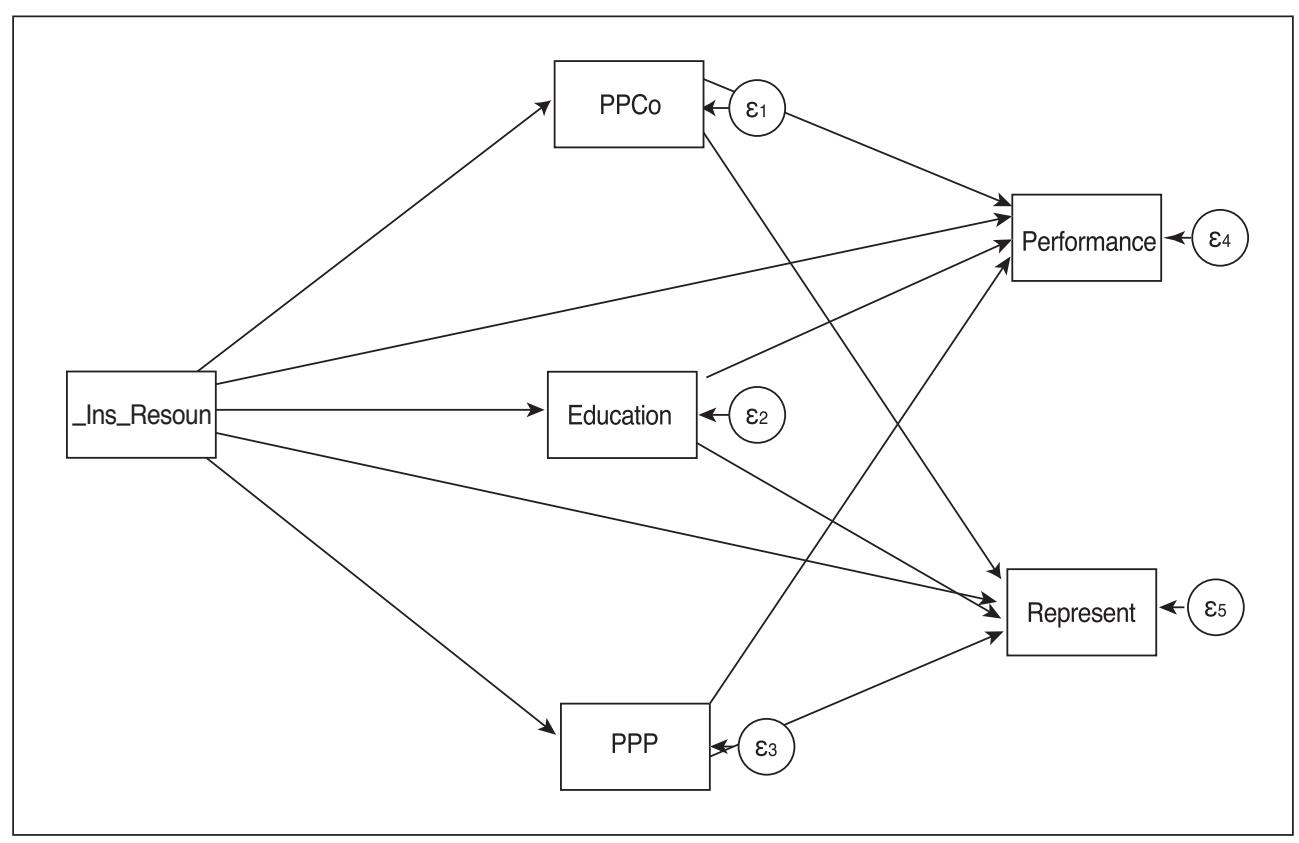

Based on the above arguments, we hypothesize that:

'Performance' and 'Representation' variables may be directly influenced by Institutional Resources, PPCo, Education, and PPP (8 Hypotheses).

H1: Institutional Resources is positively associated with Performance. 
H2: Institution al Resources is positively associated with Representation.

H3: PPCo is positively associated with Performance.

H4: PPCo is positively associated with Representation.

H5: Education is positively associated with Performance.

H6: Education is positively associated with Representation.

H7: PPP is positively associated with Performance.

H8: PPP is positively associated with Representation.

A direct effect is defined as an effect wherein a variable has a direct impact on another variable. Three parameter variables (PPCo, Education, and PPP) may also be directly affected by Institutional Resources variable (3 Hypotheses).

H 9: PPCo is positively associated with Institutional Resources.

H10: Education is positively associated with Institutional Resources.

H 11: PPP is positively associated with Institutional Resources.

\section{FINDINGS AND RESULTS}

As explained above, this study focuses on verifying the 11 hypotheses in relation to the six concise (extracted) indicators - The 'Performance' and 'Representation' variables are positively associated with 'Institutional Resources,' 'PPCo,' 'PPP,' and 'Education.' In the summary statistics, there are the following results in terms of six variables and 18 sub-variables (see Table 2. below). The quantitatively-extracted variables' units consist of number $(\mathrm{N})$, amount $(\mathrm{A})$, proportion $(\mathrm{P})$, and time $(\mathrm{T})$. Particularly, looking at the mean of each variable field, in the Institution 'administrative personnel' 1.4 persons was shown, 'establishment/revision of ordinance' -8.02 times, and 'budget' $-4,792,000$ Korean won; in the PPCo, 'executive sessions' were held 3.12 times, 'briefing sessions' 1.83 times, 'WFC task force' 0.5 times, and 'workshops' 0.83 times; in Education, 'civil servants' education' $-30.7 \%$ of civil servants participated, in 'seniors' education' $21.49 \%$ participated, 'civil education' was held for 7.65 hour; in the PPP 'WFC committee members' -19.52 persons, 'consultative group members' -13.54 persons, and 'civic group members' -63.6 (192.4) persons. ${ }^{3}$

3. In several local governments, the criteria of civic group membership are measured too roughly. Except for such cases, the average number of civic group members is 63.6. 
Table 2. Summary of Variables

\begin{tabular}{|c|c|c|c|c|c|}
\hline \multicolumn{2}{|r|}{ Variable } & Mean & Std. Dev. & Min & Max \\
\hline \multirow{3}{*}{$\begin{array}{l}\text { Institutional } \\
\text { Resources }\end{array}$} & administrative personnel $(\mathrm{N})$ & 1.40 & 0.60 & 1 & 13 \\
\hline & establishment revision of ordinance $(\mathrm{N})$ & 8.02 & 2.68 & 0 & 114 \\
\hline & budget(A) $(\$ 1,000)$ & 47.92 & 282.05 & 0 & 1960 \\
\hline \multirow{4}{*}{ PPCo } & executive sessions $(\mathrm{N})$ & 3.12 & 2.82 & 0 & 9 \\
\hline & briefing sessions $(\mathrm{N})$ & 1.83 & 2.24 & 0 & 8 \\
\hline & WFC task force $(\mathrm{N})$ & 0.5 & 0.71 & 0 & 2 \\
\hline & workshops for seeking tasks $(\mathrm{N})$ & 0.48 & 0.77 & 0 & 3 \\
\hline \multirow{3}{*}{ Education } & civil servants' education $(\mathrm{P})$ & 30.70 & 38.60 & 0 & 100 \\
\hline & seniors' education $(\mathrm{P})$ & 21.49 & 28.95 & 0 & 100 \\
\hline & civil education $(\mathrm{T})$ & 7.65 & 11.72 & 0 & 55 \\
\hline \multirow{3}{*}{ PPP } & WFC committee members $(\mathrm{N})$ & 19.52 & 29.43 & 0 & 154 \\
\hline & consultative group members $(\mathrm{N})$ & 13.54 & 15.97 & 0 & 90 \\
\hline & civic group members $(\mathrm{N})$ & $192.40^{*}$ & 915.70 & 0 & 6351 \\
\hline \multirow{2}{*}{ Performance } & typical project number $(\mathrm{N})$ & 9.65 & 15.56 & 0 & 80 \\
\hline & whole project number(N) & 25.6 & 26.50 & 0 & 118 \\
\hline \multirow{3}{*}{$\begin{array}{l}\text { Represen- } \\
\text { tation }\end{array}$} & $\begin{array}{l}\text { the female proportion of senior civil } \\
\text { servants }(P)\end{array}$ & 11.70 & 4.99 & 2.30 & 24.20 \\
\hline & $\begin{array}{l}\text { the female proportion of committee } \\
\text { members }(\mathrm{P})\end{array}$ & 37.83 & 7.87 & 14.30 & 50.40 \\
\hline & $\begin{array}{l}\text { the female proportion of community } \\
\text { center members }(P)\end{array}$ & 33.71 & 6.04 & 22.60 & 46.60 \\
\hline
\end{tabular}

In the Performance, 9.65 typical projects were carried out on average and the average whole-project number was 25.6. In the Representation 'the female proportion of senior civil servants' $-11.7 \%$, 'the female proportion of (local government) committee members' $-37.83 \%$, and the female proportion of community center ${ }^{4}$ members $33.71 \%$. The final figure is shown as a positive and progressive outcome because the average female proportion of community centers in the main metropolitan areas was $32.5 \%, 1.2 \%$ lower than the average of the WFC cities (Choi, et al. 2014).

The analysis results of the structural model (path analysis) through paths between independent ('Institution al Resources,' parametric ('PPCo,' 'PPP,' 'Education'), and dependent variables ('Performance,' 'Representation') are presented in Table 3. below.

4. The community centers (around 3,000 in 2013) have been established based on the Local Government Act since 1999, which aims to increase all residents' quality of life, and are managed by each community committee. 
Table 3. The Results of Path Coefficient

\begin{tabular}{|c|c|c|c|c|c|}
\hline Hypothesis & \multicolumn{3}{|c|}{ Hypothesized relationship } & Path coefficient & P-Value \\
\hline $\mathrm{H} 1$ & \multicolumn{3}{|c|}{ Institutional Resources $\rightarrow$ Performance (+) } & 1.413705 & $(0.04)^{\star \star}$ \\
\hline $\mathrm{H} 2$ & \multicolumn{3}{|c|}{ Institutional Resources $\rightarrow$ Representation (-) } & -.4449953 & $(0.275)$ \\
\hline $\mathrm{H} 3$ & \multicolumn{3}{|c|}{ PPCo $\rightarrow$ Performance $(+)$} & 2.74453 & $(0.035)^{\star \star}$ \\
\hline $\mathrm{H} 4$ & \multicolumn{3}{|c|}{ PPCo $\rightarrow$ Representation (+) } & 1.740082 & $(0.23)^{\star \star}$ \\
\hline $\mathrm{H} 5$ & \multicolumn{3}{|c|}{ Education $\rightarrow$ performance $(+)$} & 0.77408 & $(0.114)$ \\
\hline $\mathrm{H} 6$ & \multicolumn{3}{|c|}{ Education $\rightarrow$ Representation( -) } & -.0716477 & $(0.133)$ \\
\hline $\mathrm{H} 7$ & \multicolumn{3}{|c|}{ PPP $\rightarrow$ Performance (-) } & -.097436 & $(0.176)$ \\
\hline $\mathrm{H} 8$ & \multicolumn{3}{|c|}{ PPP $\rightarrow$ Representation (+) } & .0714648 & $(0.024)^{\star \star}$ \\
\hline $\mathrm{H} 9$ & \multicolumn{3}{|c|}{ Institutional Resources $\rightarrow$ PPCo (-) } & -.1039154 & $(0.299)$ \\
\hline $\mathrm{H} 10$ & \multicolumn{3}{|c|}{ Institutional Resources $\rightarrow$ Education (-) } & -3.755113 & $(0.186)$ \\
\hline $\mathrm{H} 11$ & \multicolumn{3}{|c|}{ Institutional Resources $\rightarrow$ PPP (+) } & .580043 & $(0.811)$ \\
\hline Variables & Performance & Representation & PPCo & Education & PPP \\
\hline $\begin{array}{l}\text { Institutional } \\
\text { Resources }\end{array}$ & $\begin{array}{r}1.4137505 \\
(\mathbf{0 . 0 4})^{\star *} \\
\end{array}$ & $\begin{array}{r}-4449953 \\
(0.275) \\
\end{array}$ & $\begin{array}{r}-.1039154 \\
(0.299) \\
\end{array}$ & $\begin{array}{r}-3.755113 \\
(0.186) \\
\end{array}$ & $\begin{array}{r}.5580043 \\
(0.811) \\
\end{array}$ \\
\hline PPCo & $\begin{array}{c}2.794453 \\
(0.035)^{\star *}\end{array}$ & $\begin{array}{c}1.740082 \\
(\mathbf{0 . 0 2 3})^{\star *}\end{array}$ & & & \\
\hline Education & $\begin{array}{r}.077408 \\
(0.114)\end{array}$ & $\begin{array}{r}-.0716477 \\
(0.133)\end{array}$ & & & \\
\hline PPP & $\begin{array}{r}-.0974336 \\
(0.176)\end{array}$ & $\begin{array}{l}.0714648 \\
(0.024)^{\star *}\end{array}$ & & & \\
\hline
\end{tabular}

The variables enumerated horizontally are endogenous variables affected by other variables, while variables marked vertically are variables influencing other variables. Among them, there is an exogenous variable, Institution al Resources,' which has an impact on other variables independently, and the others are intermediate variables (PPCo, Education, and PPP).

Consistent with the mechanism of alternative monitoring framework, we found that two dependent variables - 'Performance' and 'Representation' - are significantly influenced by 'Institution al Resources', 'PPCo,' and 'PPP' $(\mathrm{p}<0.05)$. There were four significant paths revealed as the following: 'Performance' was significantly associated with "Institution al Resources" (p-value: 0.04) - consistent with Hypothesis 1 - and 
'PPCo' (p-value: 0.035 ) - consistent with Hypothesis 3. The statistical relationships between 'Institution al Resources" and 'Performance,' and 'PPCo' and 'Performance' show positive (+) directions. Also, 'Representation' was strongly related to 'PPCo' (p-value: 0.023 ) - consistent with Hypothesis 4, and 'PPP' (p-value: 0.024) - consistent with Hypothesis 8 . They present the positive $(+)$ directions between 'PPCo' and 'Presentation,' and 'PPP' and 'Presentation' (see Table 3. above).

In particular, 'PPCo' has a positive $(+)$ correlation with both dependent variables ('Performance' and 'Representation'), verifying the statistical influence at p-value $<0.05$. Also, there may be a direct relationship of 'Institution al Resources" and 'Representation' via 'PPP' by having the positive (+) directions; although the relationship between 'Institution al Resources" and 'PPP' is not statistically significant ( $\mathrm{p}>0.05)$. Meanwhile, one of parametric variables, 'Education,' has no significant influence on either of the dependent variables ('Performance' and 'Representation'); a positive direction to 'Performance' and a negative (-) correlation with 'Representation,' but the statistical significance is not confirmed ( $p>0.05)$. Overall, even though it was not possible to verify the statistical influence, five of the 11 hypotheses $(\mathrm{H} \mathrm{2,} \mathrm{6,} \mathrm{7,} \mathrm{9,} \mathrm{and} \mathrm{10)}$ have negative $(-)$ relationships.

Figure 6. The Result of Path Analysis

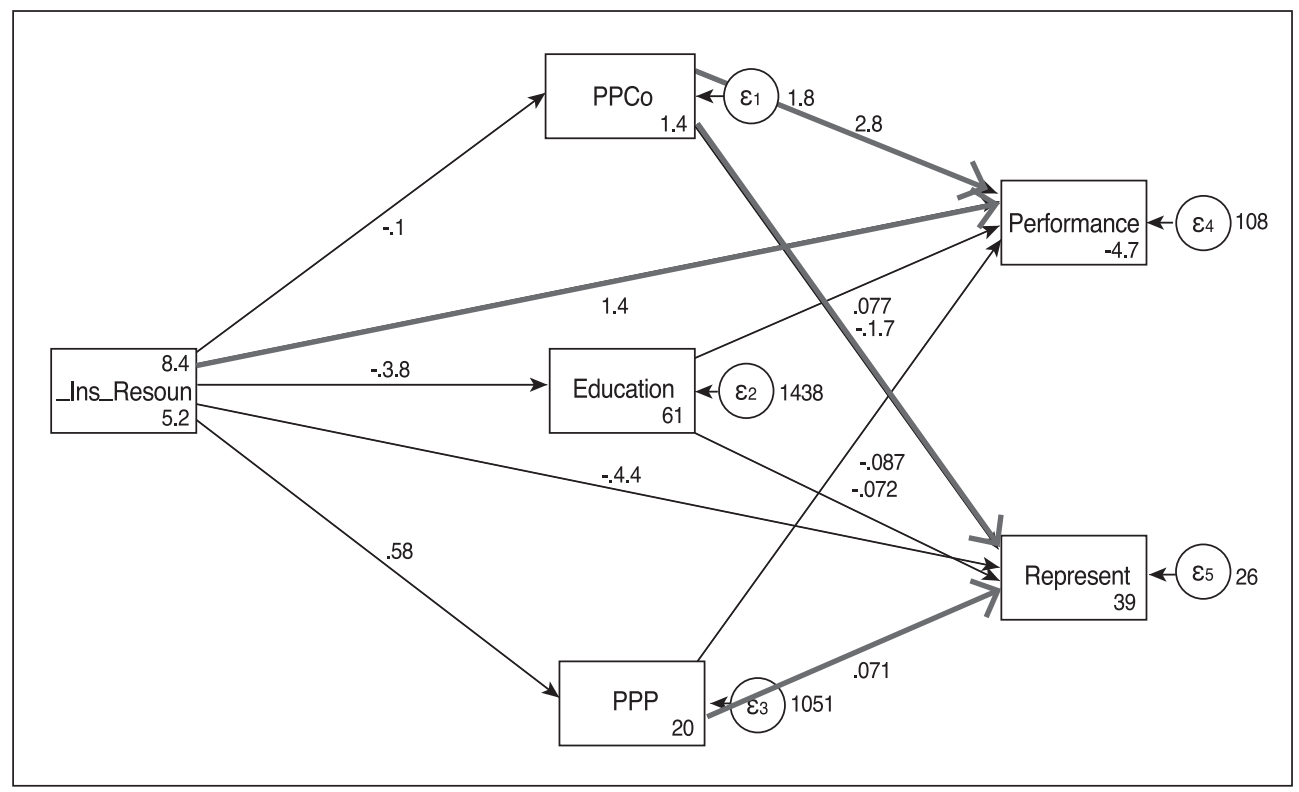

The Korean Journal of Policy Studies 


\section{DISCUSSION AND CONCLUSIONS}

This study tried to look at the mutual relationship between the factors (indicators) of the alternative monitoring framework of the WFC project. The path analysis was carried out to analyze the relationship between six variables - independent (Institutional Resources), parametric (PPCo, Education, PPP) and dependent (Performance and Representation)- that highlight and summarize the 10 indicators and 29 detailed indicators of the alternative monitoring framework. As a result, it was found that 'Institution al Resources,' 'PPCo,' and 'PPP' had a significant influence on 'Performance' and 'Representation.' In particular, there were four statistical associations (paths): (1) 'Institutional Resources $\rightarrow$ Performance' (p-value: 0.04), (2) 'PPCo $\rightarrow$ Performance' (p-value: 0.035), (3) 'PPCo $\rightarrow$ Representation' (p-value: 0.023), and (4) 'PPP $\rightarrow$ Representation' (p-value: 0.024).

The direct path of 'Institutional Resources $\rightarrow$ Performance' is in line with the argument that the institutional arrangements, including administrative personnel, ordinance, and budget, have an impact on creating and developing various WFC detailed projects. In other words, it means that the WFC project, with a firm personnel composition of department, legal basis through a series of establishment and revision, and budget, can set up and develop a variety of detailed programs in the local communities. This result is consistent with previous research undertaken on the positive relationship between an institutional foundation and mechanism, and local government performance (American Management Association, 2007), (Arthur, 1994), (Brewer and Selden, 2000), (Kim et al., 2008).

The direct relationship of 'PPCo $\rightarrow$ Performance' presents the concept that cooperation between the various departments in local government (symbolized as executive sessions, 'briefing sessions' 'WFC TF,' and workshops) plays a critical role in extending the WFC project and embedding it within the local community. For example, caring projects (related to one of the four values and five targets of the WFC project (Figure 1.)) are multilateral tasks requiring a cooperative way to deal with administrative issues of daycare centers, balance of work and family, road safety facility, convenient public transportation system, and so on. Hence, the administrative staff of each relevant department is recommended to build up a partnership of sharing and discussing related information on the process of projects being managed by each department and to try to find ways of linking such various projects to the integrated context of the WFC project.

Also, in line with the above relationship, the direct association of 'PPCo $\rightarrow$ Representation' demonstrates the possibility that a robust cooperation of departments might enhance the view of gender sensibility and understanding of implementing departmen- 
tal tasks, which can therefore have a direct or indirect influence on women's representation in relation to a gender composition of task-related organizations (the female proportion of senior civil servants, committee members, and community center members). For instance, in carrying out urban planning projects in the WFC governments, implementing departments may attempt to encourage female civil servants, experts and citizens to participate in a project process in order to reflect the gender-specific needs in urban planning facilities, such as women-friendly roads, care center amenities, etc. As a result of such attempts, a variety of opportunities to take a part in the decision-making processes will exist for female civil servants, experts, and citizens.

The direct path of 'PPP $\rightarrow$ Representation' corresponds with the existing research literature on the performance of the former in relation to raising the capacity of civic groups and citizens, and supports various participatory opportunities in a decision-making process (Stirling, 2009; Pawar and Huh, 2014; Jung, 2014). In particular, the PPP arrangements of the WFC governments were institutionally well-organized and characterized by the triangular bodies of partnership: the WFC committee, ${ }^{5}$ the consultative group, ${ }^{6}$ and the civic group. ${ }^{7}$ The $50 \mathrm{WFC}$ governments tried to formulate a 'good governance' composition of the three bodies, including relevant departmental staff, council members, experts, companies, local NGOs, and community citizens. ${ }^{8}$ Hence, such an organizational basis and efforts to build a partnership made a very positive contribution to enhancing the female proportion of partnership bodies. In particular, through the activities of the WFC civic group related to participating in, not only the process of detailed WFC projects, but also the decision-making levels of local governments, many female members were able to increase their capacity and this led to an important step in improving the awareness of such women's capacity and experience in the governmental sector. Consequently, it was shown as being connected to the result of expansion of involvement in various committees of the local governments and community centers (committees).

5. The WFC committee is an advisory or decision-making body in terms of establishing or revising ordinances and budgets related to WFC project.

6. The consultative group is a comprehensive cooperation body formed to achieve the goals of WFC in which mainly voluntary stakeholders, including experts, companies, local NGOs, and community citizens, take part.

7. The civic group of WFC consists of female citizens from all backgrounds and participates, not only in the process of detailed projects of WFC, but also at the decision-making level of local government.

8. According to the survey results, the triangular bodies of partnership of WFC government consist of various stakeholders from, not only the public sector (33-55\%), but also the private (10-25\%) and voluntary sectors (25-66\%). 
Moreover, the direct $(+)$ path constitution from 'Institutional Resources' and 'Representation' via 'PPP' - not statistically significant ('Institution al Resources' $\rightarrow$ 'PPP') - may demonstrate the fact that the institutional basis (ordinances, budget, and personnel) has a positive influence on PPP in terms of the establishment, composition, and management of partnership bodies. Also, such influence leads to the outcome of the extension of women's representation since female NGO members and residents could take on a role of 'co-producer' and even 'agenda-setter' rather than 'simple participants' (Huh, 2011). This highlights the argument that the institutional basis could provide momentum of robust cooperation recurring more often, beyond the positions and origins of stakeholders from the voluntary sectors (Rainey and Steinbauer, 1999), (OECD, 2005), (Kettl and Goldsmith, 2009).

Meanwhile, despite the above empirical findings and results, this study has limitations in relation to embracing and reflecting the qualitative contents (indicators) that are embedded in the alternative monitoring framework. Through a monitoring of quantitative and qualitative contents, we can reach more realistic and substantive field results and outcomes. For example, particularly why the 'Education' variable had no significant association with 'Performance' and 'Representation,' and how 5 negative (-) paths (correlation) were shown in the path constitution, yet were not statistically significant.

Therefore, further research needs to adopt a more embracing methodology in order to analyze, not only quantitative variables, but also qualitative ones, and also to compare both aspects in a comprehensive way.

\section{REFERENCES}

American Management Association. 2007. HOW TO BUILD A HIGH-PERFORMANCE ORGANIZATION. New York: American Management Association.

Arthur JB. 1994. "Effects of Human Resource Systems on Manufacturing Performance and Turnover." The Academy of Management Journal 37(3): 670-687.

Brewer GA, Selden SC. 2000. "Why Elephants Gallop: Assessing and Predicting Organizational Performance in Federal Agencies." Journal of Public Administration Research and Theory 10(4): 685-711.

Chapman. J. 2004. Politics, Feminism and the Reformation of Gender. Routledge.

Halford, S. 1992. "Feminist change in a patriarchal institution: the experience of women's initiatives in local government." in Gender and Bureaucracy, edited by M. Savage and A. Witz. Oxford: Blackwell. 
Halford, S. Savage, M. and Witz, A. 1997. Gender, Careers and Organisatons. London: Macmillan.

Hayden, D. 1995. The Power of Place. New Haven: Yale University Press.

Jung, W. 2014. "Evaluation of the Citizen-Participatory Budgeting System and Problems." Journal of Korean Local Government Studies 16(2): 241-257.

Kim EH, Kim HS, Park HS. 2008. "The Effect of Organizational Environment Characteristics on Civil Servants' Innovative Work Behavior in Local Government." The Korean Journal of Local Government Studies 12(4): 7-32.

Kubisch AC. 1996. Comprehensive Community Initiatives: Lessons in Neighborhood Transformation, Toronto: Wellesley Institute.

Kim YH. and Moon, YK. 2008a. A Study on Development of Gender Mainstreamrelated Institutions. Seoul: KWDI(Korean Women's Development Institute).

Kim YH. and Moon, YK. 2008b. The Establishment of Policy Paradigm Towards Multi-National/Cultural Society. Seoul: KWDI(Korean Women's Development Institute).

Moon, YK. and Ma, YH. 2010. The Manual of Women-Friendly City, Seoul: KWDI (Korean Women's Development Institute).

Moon, YK. and Ma, YH. 2012. Creation of the Monitoring Indicators of WomenFriendly City and Analysis on the Implementation Status. Seoul: KWDI(Korean Women's Development Institute).

Choi, YJ. and Yoo, HJ. 2013. Analysis on the Implementation Status of WomenFriendly City and Mid-Long Term Development Plan. Seoul: KWDI(Korean Women's Development Institute).

Choi, YJ., Yoo, HJ., and Huh, TW. 2014. The Creation Plan of Women Jobs through the Revitalization of Women Participation of Citizen Autonomy. Seoul: KWDI(Korean Women's Development Institute).

Huh, TW. 2017. "Analyzing the Configuration of Knowledge Transfer of the Green Island Projects in S. Korea." The Korean Journal of Policy Studies. 32(1): 1-26.

Laws, G. 1994. "Social justice and urban politics: an introduction." Urban Geography 15: 603-11.

1997. "Women's life course, spatial mobility and state policies." in Thresholds in Feminist Geography, edited by J. P. Jones III, H. Nast and S. Roberts. New York: Powman and Littlefield.

Marcoulides, George A. and Saunders, Carol. 2006. "PLS: A Silver Bullet?," MIS Quarterly, Vol. 30 No. 2, pp. iii-ix/June 2006.

McDowell, L. 1999. GENDER, IDENTITY \& PLACE: Understanding Feminist Geographies. Polity Press Ltd., Cambridge.

Nora, A. 2004. "Path Analysis: An introduction and Analysis of Decade of Research." 
Journal of Educational Research 98(1): 5-12.

OECD. 2005. Modernizing Government: The Way Forward. Paris: OECD.

Pawar, M. and Huh, TW. 2014. "Korean Response to Environmental Challenges: Origins, Drivers and Impacts of Green Growth on Development." in Learning from the South Korean Developmental Success: Effective Developmental Cooperation and Synergistic Institutions and Policies, edited by I. Yi and T. Mkandawire. UNRISD. Palgrave Macmillan.

Perkins, T. 2002. Comprehensive Community Initiatives (CCI): A Comparison of Community Implementation Plans. University of Nebraska Public Policy Center.

Rainey, HG. and Steinbauer, P. 1999. "Galloping Elephants: Developing Elements of a Theory of Effective Government Organizations." Journal of Public Administration Research and Theory 9(1): 1-32.

Song, HS. and Park, TW. 2013. "Urban Planning Criteria for Women-friendly City by AHP." Journal of Urban Management 26(4): 361-383.

Stirling, A. 2009. "Participation, precaution and reflexive governance for sustainable development." in Governing Sustainability, edited by N. Adger and A. Jordan. Cambridge: Cambridge University Press.

Torjman, S. and Leviten-Reid E. 2003. Comprehensive Community Initiatives, The Caledon Institute of Social Policy. Ottawa, Ontario, Canada..

Vafaei, A., Ahmed, T., Freire ANF., Zunzunegui, M.V., and Guerra, R. O. 2016. "Depression, Sex and Gender Roles in Older Adult Populations: The International Mobility in Aging Study (IMIAS)." PLOS ONE.

Valentine, G. 1990. "Women's fear and the design of public space." Built Environment 16: 288-303.

Weiss, CH. 1995. "Nothing as Practical as Good Theory: Exploring Theory-based Evaluation for Comprehensive Community Initiatives for Children and Families." in New Approaches to Evaluating Community Initiatives: Concepts, Methods, and Contexts, edited by James Connell et al. Washington, DC: Aspen Institute.

Wolfle, LM. 2003. "The introduction of Path Analysis to the Social Sciences, and Some Emergent Themes: An Annotated Bibliography." Structural Equation Modeling 10(1): 1-34. 
